\title{
The Effects of Agile Methodologies on Software Project Management in Pakistani Software Companies
}

\author{
Javed Iqbal', Mazni Omar², Azman Yasin ${ }^{3}$ \\ ${ }^{1,2,3}$ School of Computing, Universiti Utara Malaysia, Malaysia \\ ${ }^{1}$ Department of Computer Science, University of Peshawar, Pakistan \\ javaidiq@uop.edu.pk ${ }^{1}$, mazni@uum.edu.my ${ }^{2}$, yazman@uum.edu.my ${ }^{3}$
}

Article History: Received: 10 November 2020; Revised: 12 January 2021; Accepted: 27 January 2021;

Published online: 05 April 2021

\begin{abstract}
Agile methodologies are always tends to increase the quality of software and also handling the complex software projects. However, the software companies in Pakistan have recently felt the disparity of producing successful software. In this context, an extensive survey has been conducted in 52 prominent software development companies of Pakistan to identify this remedy and the motivation behind this production discrepancy. It is revealed from the survey that there is a lack of empirical evidence in the relationship of agile methodologies with the effective and progressive management of software project management factors including, schedule, scope, risk, budget, quality and resources. Therefore, the proposed study delivers an extensive statistical comparison to determine the effectiveness of agile methodologies in terms of their effects on the project management factors. The results suggest that in general all agile methodologies play a significant role towards the successful software development in the software company. However, Extreme Programming, Scrum, Kanban and Agile modeling are the main determinants of production disparity among software companies. Furthermore, it is determined that the quality factor has a positive correlation with the rest of the factors. It is also found that the budget factor has significantly correlated with other five factors, while rest of the factors has insignificant correlation. We have also compared agile methodologies in terms of project management factors, which specify that each agile methodology has its own importance and effect with respect to managing different factors of project management.
\end{abstract}

Keywords: Agile Methodologies, Project Management factors, Pakistani Software Companies, Software Development

\section{Introduction}

Numerous methods for software production are invented and used in the software companies for the last few decades. Each methodology has its own uniqueness that differentiates it from other software methodologies. These methods can be categorized as either heavyweight or lightweight methods. The heavyweight methods are considered to be conventional formal methods that focus on exhaustive planning and heavy documentations. On the other side the lightweight methods, also known as agile methods focus on individual interactions rather than processes and tools. These methods focus on working software instead of comprehensive documentations. Furthermore, customer collaboration is considered more than a contract negotiation and always welcome to the change whenever it comes in the software instead of follows a strategy. The traditional methods are still extensively used by the software companies, but due to a number of challenges the software project goes into failure. In 1950's, several methods were designed for the development and management of softwares. These methods were included incremental and iterative methods [1]. Few of them were linear, also recognized as "Waterfall Model"[2]. Waterfall model has the sequential nature and the most adopted method in the real system design [3]. This method has problem of dealing the client requirements, rapid change of domain organization, delivery time the project costing [4]. In the response to handle these problems of Waterfall model, the idea of agile methodologies were introduced in 2001 [5]. Agile methodologies targeted to overcome the shortcomings such as complication, heavy paperwork and costly design of pretended heavyweight software methodologies [6].

Globally, the software companies have adopted the agile methodologies to increase their software productivity and quality. Hence, software companies in Pakistan also moved towards the agile methodologies since a decade now. In this study, we try to find that how much these agile methodologies are adopted by the software professional in Pakistani software companies by conducting a widespread online survey in four different big cities. The survey conducted in Pakistani software companies showed that there is a lack of empirical evidence to determine that which agile method has been used broadly and to determine the relationship with the project management (PM) factors of six-pointed star model of the Project Management Body of Knowledge (PMBOK) [7]. The aim of this research is to identify the effect of agile methodologies with respect to different PM factors. Software companies in Pakistan are using agile methodologies for more than a decade now but there is no enough evidence available based on empirical analysis for choosing a desired agile method. Therefore, this research is a first effort to identify empirically the effectiveness of agile methodologies with respect to their effect on PM factors, comparison of agile 
methodologies and agile software development (ASD) success in Pakistani software companies. Finally, there is a comparison of all seven agile methodologies with each other with respect to their effect on the six-point star model factors. Howard Lei et al., has been compared and analyzed the Scrum and Kanban methodologies [8]. However, in this paper we are extensively comparing and analyzing agile methodologies including 1) Extreme programming (XP), 2) Scrum, 3) Agile Modeling (AM), 4) Kanban, 5) Lean, 6) Crystal, and 7) Feature driven development (FDD) on the respondents responses. Statistical techniques such as correlation were applied to investigate the outcomes of this study. After compiling the results it has been observed that the quality factor has a positive correlation with all other five PM factors and statistically significant correlation with the budget factor, while statistically insignificantly correlated with all other factors. Additionally, it is also revealed the most extensively used agile methodology is XP followed by Scrum methodology in Pakistan software companies. Furthermore, these seven agile methodologies are compared with respect to PM factors, which indicated that each agile methodology play its own role in successful software development and also taking significant part in the development of successful software projects.

Consequently, the paper is structured as follows: The Section 2 presents the Literature review in our study. In Section 3 we present the methodology used for research and Section 4 explain the discussions and results. Conclusion and suggestions for future study is presented in Section 5.

\section{Literature Review}

\subsection{Agile Methodologies and Critical Success Factors}

This section demonstrates the progression of ASD generally and specifically in Pakistani software industry and their application. The survey conducted at the software development companies in Pakistan has shown a strong inclination towards agile methodologies such as XP, Scrum, Kanban, AM, lean, crystal methodologies and FDD. Many software methodologies have been invented and used in the software development companies for the last few decades. Each methodology has its own uniqueness that differentiates it from other software methodologies. These methods can be categorized as either heavyweight or lightweight methods. The heavyweight methods are considered to be conventional formal methods that focus on exhaustive planning and heavy documentations. On the other side the lightweight methods, also known as agile methods focus on individual interactions rather than processes and tools. These methods focus on working software instead of comprehensive documentations. Furthermore, customer collaboration is considered more than a contract negotiation and always welcome to the change whenever it comes in the software instead of follows a plan. Conventional methods are facing several challenges, which cause software projects failure. The agility of software development has a broad spectrum that can be defined in several ways [9-11].

The proposed research is based on the utmost prominent agile methods used among Pakistani software companies are: XP [12], Scrum [13], Kanban [14], Crystal [15], Lean Software Development [16], (AM) [17], FDD [18] and some hybrid methods according to the survey respondents. Each agile methodology has exceptionality unique and exhibit some shared features and practices to implement. There is a firm liaison between the project success and efficiency [19]. The agile methodology is based on the "iterative enhancement" [20] technique [21]. Agile is having an iterative nature methodology, the working software delivers in small iterations and every iteration is autonomous Software Development Life Cycle (SDLC) by itself [22]. Unlike the Spiral model [21], agile methods adopt easiness in all practices [23]. The rest of methodologies are intermingling with each other. The software project success criteria has been studied by numerous authors. In a recent study, Iqbal compared three agile methodologies, including XP, Scrum and Kanban, and it was found that Kanban performed better as compared to Scrum and XP [24]. Scrum and Kanban methods has been compared statistically to analyze their effect in terms of PM factors for the development of software projects [8]. In another study, Akbar has compared the effect of heavyweight and lightweight methods using six-point star model factors and how these factors were relating with each other. The results revealed that lightweight methods were better for small-scale, while heavyweight methods were better for large-scale softwares [10]. In another research, the author conducted a survey and involved diverse users in the SDLC to assess the factors for the software quality on the base of their perception and experience [25]. A software development model "AZ-Model" was introduced on the basis of six-pointed star model of PM [9]. Sanchez introduced in his research that Cost and Time Project Management Success (CTPMS) is one of the important step for software products [26]. Four different attributes including Quality, Scope, Time and Cost have used to determine the observed level of project success in general, 19 failure and 36 success factors are identified for these four attributes [27].

It is also discovered that agility of software development is due to the project environmental factor and the 
strength of project team. Furthermore, these factors can help experts to reflect on their development practices as well as to discuss the changes to get upper rates of project success [28]. The effect of agile methodologies have an optimistic impact on the efficiency and overall customer satisfaction of project success [29]. The implicit usage of lean and agile help coping with complexity. The authors proposed that lean development along with agile PM are assuming as a possible solution to handle with project complexity [30]. Rasch Measurement Model Analysis is used to identify the success factor in agile development. The over budgeted software fails due to the unrealistic cost management [31]. A survey is used to identify the different characteristics of successful projects in delivering customer reward. Furthermore, the author proposed that the successful software projects are different from the less successful one in delivering customer profit in different ways [32]. In another study the author investigated the role of maturity driven process improvement in a software company [33].

\subsection{Quality Management Success Factor}

Quality is an indicator for successful software projects and one of the essential step to achieve the quality and successful software is to accomplish the customer's requirements. The clients requirements and satisfaction is a popular saying and definition of the quality software [34]. According to a recent study [35], the author suggested that ISO 9126 software quality model of 2001 is broadly established and well-known model. The author further suggested regarding the significance of the model in assessing the quality of the software across diverse domains. In this paper, we are using the six-point star model to measure the quality factor, which is an indicator of successful project with the rest of PM factors. For the purpose, we have administered a survey and used correlation technique between the quality factor and other five factors of PM. The outcome showed that the quality factor has a positive correlation with other factors, which indicates the success of software projects. Agile methodologies have better scores in the context of customer satisfaction, success of project and fulfilling the quality requirement as compared to conventional methodologies [10].

\section{Research Methodology}

Figure 1 shows the six-point star model, which is used to analyze agile methodologies in the context of PM factors instead of traditionally used factors. According to Chatfield, traditionally Cost, Time and Scope are the three key factors to measure the project success [36]. Later on, PMBOK 4.0 presented an improved model for developing successful software projects, which was established on six factors including (schedule, scope, cost, risk, resources and quality) $[13,37]$. The model contained two triangles as shown in Figure 1. The first triangle indicates input/output factors (schedule, scope, and budget) of the project, whereas the other triangle shows the process factors (risk, resources, and quality).

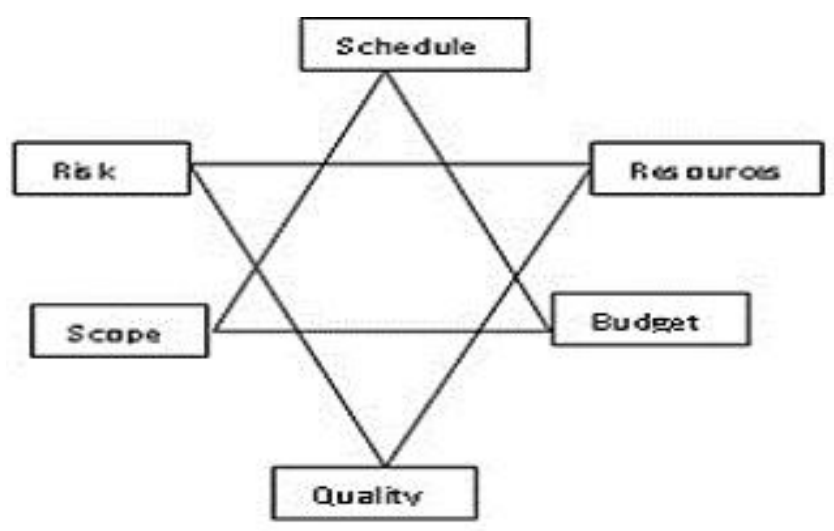

Figure 1. Six-point star model of PMBOK4.0 [7]

This research is based on a quantitative study made with software professional from the software companies to determine the effect of agile methodologies in the context of PM factors. Each factor has a significant role and importance to produce successful software projects using agile methodologies.

\subsection{Data Collection}

An online survey (using http://www.googledocs.com) was designed to gather the software professionals' responses in 52 software companies of four largest cities of Pakistan, where most of the software companies are located. A well-established questionnaire is adopted for this study, presented by [8]. This questionnaire is adopted 
because it is suitable for the measurement of successful agile implementation, such as $[9,10]$. The questionnaire has contained two sections, section one comprises the information regarding the respondents while section two comprises the questions pertained to the factors of six-point star model. Data were collected between April 2017 May 2017. Table 1, indicates the six-point star model factors relating with the survey questions. To categorize the responses of respondents, a Likert scale is used to get the feedback of respondents for each survey question as shown in Table 2. A numeric score has assigned to response specified by each respondent for each Likert scale. Numerical survey response data is produced on the basis of obtained numeric score. Spearman's Rank Order correlation is used to analyse the data using the statistical tool (Stata version 12).

Table 1. Survey questionnaire

\begin{tabular}{|c|c|c|}
\hline Factor & Survey questions & $\begin{array}{c}\text { Question } \\
\text { No }\end{array}$ \\
\hline Schedule & $\begin{array}{l}\text { Project team members are aware } \\
\text { of the current progress of the } \\
\text { project most of the time. } \\
\text { Project teams can react and } \\
\text { adapt to change in requirements } \\
\text { quickly and effectively. } \\
\text { Milestones are achieved } \\
\text { according to schedule. }\end{array}$ & $\begin{array}{l}\text { II } \\
\text { III }\end{array}$ \\
\hline Scope & $\begin{array}{l}\text { Project methodology and } \\
\text { features have bounded scope } \\
\text { The project methodology chosen } \\
\text { makes the software product } \\
\text { scope clear and bounded. }\end{array}$ & I \\
\hline Budget & $\begin{array}{l}\text { The Project is completed within } \\
\text { the estimated budget. } \\
\text { The Project has a good return on } \\
\text { investment (ROI). }\end{array}$ & II \\
\hline Risk & $\begin{array}{l}\text { Project risks are identified and a } \\
\text { strategy is predefined to mitigate } \\
\text { the risk. } \\
\text { Project opportunities are } \\
\text { identified and exploited to the } \\
\text { benefit. }\end{array}$ & I \\
\hline Resources & $\begin{array}{l}\text { Trained and skilled human } \\
\text { resources are easily available. } \\
\text { Software tools and techniques } \\
\text { are available or can be adapted } \\
\text { to the task. }\end{array}$ & I \\
\hline Quality & $\begin{array}{l}\text { Product quality requirements are } \\
\text { achieved. } \\
\text { Customers are satisfied with the } \\
\text { delivered product. } \\
\text { The project has been categorized } \\
\text { as successful. } \\
\text { The user interface has been } \\
\text { assessed as easy by the } \\
\text { Customers }\end{array}$ & $\begin{array}{l}\text { I } \\
\text { II } \\
\text { III } \\
\text { I V }\end{array}$ \\
\hline Question & $\begin{array}{l}\text { What agile methodologies your } \\
\text { mostly uses for developing product } \\
\text { - Extreme Programming } \\
\text { - Scrum Methodology } \\
\text { - Kanban Methodology } \\
\text { - FDD } \\
\text { - Crystal Methodology } \\
\text { - Aean Software Development } \\
\text { - Ogile Modeling } \\
\text { Others }\end{array}$ & comp: \\
\hline
\end{tabular}

Table 2. Likert Scale Response Grouping

\begin{tabular}{|l|c|}
\hline Scale & Numerical Score \\
\hline Strongly Disagree & 1 \\
\hline Disagree & 2 \\
\hline Neutral & 3 \\
\hline Agree & 4 \\
\hline Strongly Agree & 5 \\
\hline
\end{tabular}

We determined that 31 of the 52 respondents are the age 26 to 30 years, 10 respondents are the age of 31 to 40 , 8 respondents are the age of 21 to 25 , and 3 respondents are the age of 41 to 50 . It is also identified that the majority of developers are male in the software development industry. Out of 52 respondents, $78.85 \%$ were male and $21.15 \%$ were female respondents. We also determined some other characteristics of the respondents such as 
experience, $38.46 \%$ of them have experience of 3 to 5 years, $30.77 \%$ of them have experience of less than 2 years, $28.85 \%$ of them have experience of 6 to 10 years and $1.92 \%$ has experience of 10 years. This shows that the majority of respondents have experience between 3 to 5 years. Personality type of the respondents is the other characteristic, $67.31 \%$ respondents are Extrovert and $32.69 \%$ are Introvert. The education level of respondents, 28 respondents $(53.84 \%)$ has a bachelor degree while 23 respondents $(46.16 \%)$ have master's degrees. The survey was conducted in four big cities of Pakistan, which shows that 22 of respondents with a percentage of $42.31 \%$ from Peshawar, 11 respondents with a percentage of $21.15 \%$ from Lahore, 15 respondents with a percentage of $28.85 \%$ from Islamabad and 4 respondents with a percentage of $7.09 \%$ from Rawalpindi city has given their responses.

\section{Results and Discussions}

This section explains the summary of survey responses; the most used agile methodology, the relationship between agile methodologies and PM factors, and a comparison of agile methodologies in terms of PM factors in surveyed software companies using statistical techniques. Furthermore, a discussion of the results is also given.

\subsection{Summary of Survey Responses and Reliability Analysis}

The summary of responses on the basis of each factor is statistically computed in Table 3 . It shows the average score of each question, the total average score and the frequency according to Likert scale as shown in Table 2 . Table 3, shows that the values of agree and strongly agree are higher and the values of strongly disagree and disagree are lower according to the Likert scale. Hence, the results in Table 3 represents the positive response of the respondents toward the effectiveness of agile methodologies on software PM factors.

Table 3. Summary of Survey responses

\begin{tabular}{|c|c|c|c|c|c|c|c|c|}
\hline Factors & S.Q & S.D & D & $\mathbf{N}$ & A & S.A & A.S & R.C \\
\hline Schedule & $\begin{array}{l}\text { Project team members are aware of } \\
\text { the current progress of project most of } \\
\text { the time. } \\
\text { Project team can react and adapt to } \\
\text { change in requirements quickly and } \\
\text { effectively. } \\
\text { Milestones are achieved according to } \\
\text { schedule. }\end{array}$ & $\begin{array}{l}0.0 \% \\
(0) \\
0.0 \% \\
(0) \\
1.92 \% \\
(1)\end{array}$ & $\begin{array}{l}1.92 \% \\
(1) \\
7.69 \% \\
(4) \\
3.85 \% \\
(2)\end{array}$ & $\begin{array}{c}9.62 \% \\
(5) \\
11.54 \% \\
(6) \\
23.08 \% \\
(12)\end{array}$ & $\begin{array}{l}57.69 \% \\
(30) \\
59.62 \% \\
(31) \\
48.08 \% \\
(25)\end{array}$ & $\begin{array}{c}30.77 \% \\
(16) \\
21.15 \% \\
(11) \\
23.08 \% \\
(12)\end{array}$ & $\begin{array}{l}4.17 \\
3.94 \\
3.86\end{array}$ & $\begin{array}{l}52 \\
52 \\
52\end{array}$ \\
\hline Scope & $\begin{array}{l}\text { Project methodology and features } \\
\text { have bounded scope } \\
\text { The project methodology chosen } \\
\text { malkes the software product scope } \\
\text { clear and bounded. }\end{array}$ & $\begin{array}{l}3.85 \% \\
\text { (2) } \\
1.92 \% \\
\text { (1) }\end{array}$ & $\begin{array}{l}17.31 \% \\
(9) \\
1.92 \% \\
(1)\end{array}$ & $\begin{array}{l}26.92 \% \\
(14) \\
21.15 \% \\
(11)\end{array}$ & $\begin{array}{c}38.46 \% \\
(20) \\
51.92 \% \\
(27)\end{array}$ & $\begin{array}{c}13.46 \% \\
(7) \\
23.08 \% \\
(12)\end{array}$ & $\begin{array}{l}3.59 \\
4.01\end{array}$ & $\begin{array}{l}52 \\
52\end{array}$ \\
\hline Budget & $\begin{array}{l}\text { The Project is completed within the } \\
\text { estimated budget. } \\
\text { The Project has good return on } \\
\text { investment (ROI). }\end{array}$ & $\begin{array}{l}3.85 \% \\
(2) \\
0.0 \% \\
(0)\end{array}$ & $\begin{array}{l}9.62 \% \\
(5) \\
1.92 \% \\
\text { (1) }\end{array}$ & $\begin{array}{c}25.00 \% \\
(13) \\
21.15 \% \\
(11)\end{array}$ & $\begin{array}{l}44.23 \% \\
(23) \\
59.62 \% \\
(31)\end{array}$ & $\begin{array}{c}17.31 \% \\
(9) \\
17.31 \% \\
(9)\end{array}$ & $\begin{array}{l}3.61 \\
3.92\end{array}$ & $\begin{array}{l}52 \\
52\end{array}$ \\
\hline Risk & $\begin{array}{l}\text { Project risks are identified and a } \\
\text { strategy is predefined to mitigate the } \\
\text { risk. } \\
\text { Project opportumities are identified } \\
\text { and exploited to the benefit. }\end{array}$ & $\begin{array}{l}0.0 \% \\
(0) \\
0.0 \% \\
(0)\end{array}$ & $\begin{array}{c}7.69 \% \\
(4) \\
3.85 \% \\
(2)\end{array}$ & $\begin{array}{c}23.08 \% \\
(12) \\
17.31 \% \\
(9)\end{array}$ & $\begin{array}{c}50.00 \% \\
(26) \\
59.62 \% \\
(31)\end{array}$ & $\begin{array}{c}19.23 \% \\
(10) \\
19.23 \% \\
(10)\end{array}$ & $\begin{array}{l}3.80 \\
3.94\end{array}$ & $\begin{array}{l}52 \\
52\end{array}$ \\
\hline Resources & $\begin{array}{l}\text { Trained and skilled buman resources } \\
\text { are easily available. } \\
\text { Software tools and techniques are } \\
\text { available or can be adapted to the task. }\end{array}$ & $\begin{array}{l}1.92 \% \\
(1) \\
0.0 \% \\
(0)\end{array}$ & $\begin{array}{l}32.69 \% \\
(17) \\
3.85 \% \\
(2)\end{array}$ & $\begin{array}{l}23.08 \% \\
(12) \\
1154 \% \\
(6)\end{array}$ & $\begin{array}{c}34.62 \% \\
(18) \\
63.46 \% \\
(33)\end{array}$ & $\begin{array}{c}7.69 \% \\
(4) \\
21.15 \% \\
(11)\end{array}$ & $\begin{array}{l}3.13 \\
4.01\end{array}$ & $\begin{array}{l}52 \\
52\end{array}$ \\
\hline Quality & $\begin{array}{l}\text { Product quality requirements are } \\
\text { achieved. } \\
\text { Customers are satisfied with the } \\
\text { delivered product. } \\
\text { The project has been categorized as } \\
\text { successful. }\end{array}$ & $\begin{array}{l}0.0 \% \\
(0) \\
.0 \% \\
(0) \\
0.0 \% \\
(0) \\
0.0 \% \\
(0)\end{array}$ & $\begin{array}{l}0.0 \% \\
(0) \\
1.92 \% \\
(1) \\
0.0 \% \\
(0) \\
0.0 \% \\
(0)\end{array}$ & $\begin{array}{l}9.62 \% \\
(5) \\
11,54 \% \\
(11) \\
9.62 \% \\
(5) \\
9.62 \% \\
(5)\end{array}$ & $\begin{array}{l}67.31 \% \\
(35) \\
59.62 \% \\
(31) \\
71.15 \% \\
(37) \\
61.25 \% \\
(32)\end{array}$ & $\begin{array}{c}23.08 \% \\
(12) \\
26.92 \% \\
(14) \\
19.23 \% \\
(10) \\
28.85 \% \\
(15)\end{array}$ & $\begin{array}{l}4.13 \\
4.11 \\
4.09 \\
4.19\end{array}$ & $\begin{array}{l}52 \\
52 \\
52 \\
52\end{array}$ \\
\hline
\end{tabular}

S.Q = Survey Questions, S.D = Strongly Disagree, A= Agree, R.C = Response Count, A.S = Average Score

The Cronbach's alpha which measure the reliability of test items, shows the reliability of each question given in Table 4. The alpha value results in Table 4 suggested that the items have relatively high internal consistency as the resultant values are greater than 0.60, which shows that each variable has enough items Hair et al., [38]. In general, the agreed lower limit for Cronbach's alpha value is .70, it may also be acceptable to even a lower value of 0.60 that 
is also acceptable. It is also proposed that in research in psychology, Cronbach's $\alpha$ of .60 or even lower could be suitable; however, values exceeding .7 are preferable [39]. A reliability measurement of 0.6 is poor, a range of 0.7 -0.79 are acceptable, while the reliability measure of 0.8 is considered to be good [40].

Table 4. Cronbach's alpha value for each question

\begin{tabular}{|l|c|}
\hline Factors & Cronbach Alpha \\
\hline Schedule & 0.75 \\
\hline Scope & 0.75 \\
\hline Budget & 0.74 \\
\hline Risk & 0.75 \\
\hline Resources & 0.74 \\
\hline Quality & 0.75 \\
\hline
\end{tabular}

In addition, figure 2 shows the percentage analysis of agree and strongly agree for each question in terms of each PM factors.

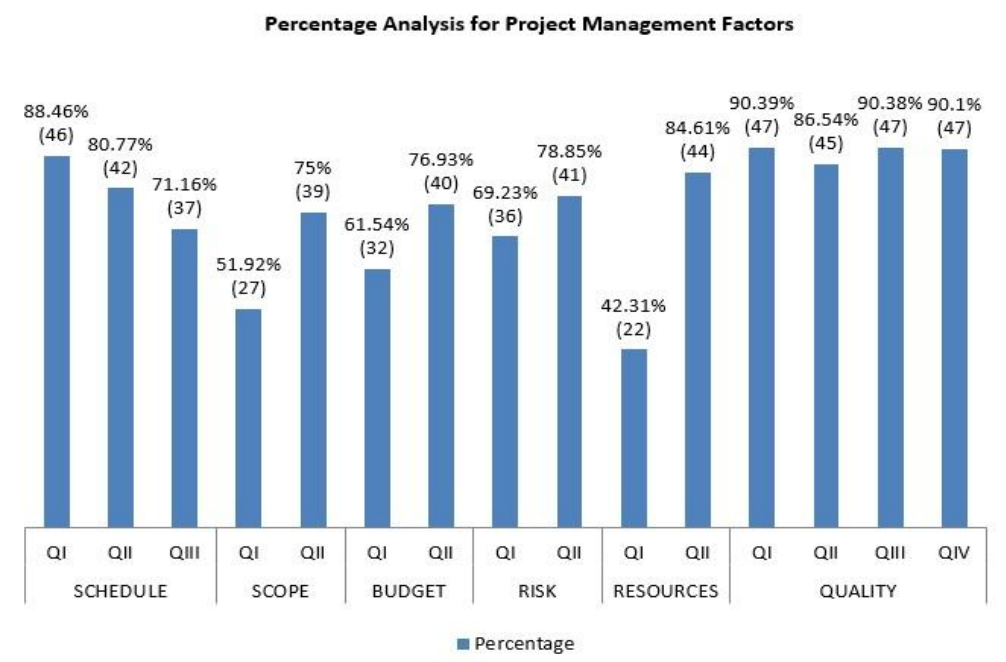

Figure 2. Shows Percentage analysis of Agree and Strongly Agree for PM

According to the responses of respondents, the average score of each Likert scale for all the six PM factors are given to evaluate the importance of the effectiveness of agile methodologies as shown in Table 5. As each factor contains two to four questions, on the base of these questions, the average score is computed. Looking to the results in Table 5, again it indicates those agree and strongly agree values are higher for each factor. For example, on the base of Q.I, Q.II and Q.III for the Schedule factor, the total average score is calculated. For scheduling factor, it describes that average score of agree and strongly agree are more than neutral, disagree and strongly disagree. These results show a positive indication according to the responses given by the respondents in terms of effectiveness and significance of agile methodologies on software PM factors

Table 5: Average Score of PM factors

\begin{tabular}{|l|c|c|c|c|c|}
\hline \multirow{2}{*}{ Factors } & $\begin{array}{c}\text { Strongly } \\
\text { Disagree }\end{array}$ & Disagree & Neutral & Agree & $\begin{array}{c}\text { Strongly } \\
\text { Agree }\end{array}$ \\
\cline { 2 - 6 } & Average & Average & Average & Average & Average \\
\hline Schedule & 0.33 & 2.33 & 7.66 & 28.66 & 13.00 \\
\hline Scope & 1.00 & 3.33 & 8.33 & 23.50 & 9.50 \\
\hline Budget & 1.00 & 3.00 & 2.00 & 27.00 & 9.00 \\
\hline Risk & 0.00 & 3.00 & 10.5 & 28.5 & 10.00 \\
\hline Resources & 0.50 & 9.50 & 10.0 & 25.5 & 7.50 \\
\hline Quality & 0.00 & 0.25 & 6.50 & 33.75 & 12.75 \\
\hline
\end{tabular}

4.2. Agile methodologies used by Respondents 
A question in Table 1 regarding the agile methodology selection was asked from the survey respondents. The feedback given by the respondents were mixed, few of them responded to just one agile method while few of them have responded to two or more methods. The collectively output showed, that XP (24 times) is broadly used agile methodology followed by Scrum (23 times), AM (20 times), Kanban (9 times), Lean (6 times), Crystal (5 times), FDD ( 3 times), and others (4 times). This shows that these software companies in Pakistan are extensively accepting these methodologies. Figure 3 shows the frequency and percentage of agile methodologies used individually according to the respondent's feedback.

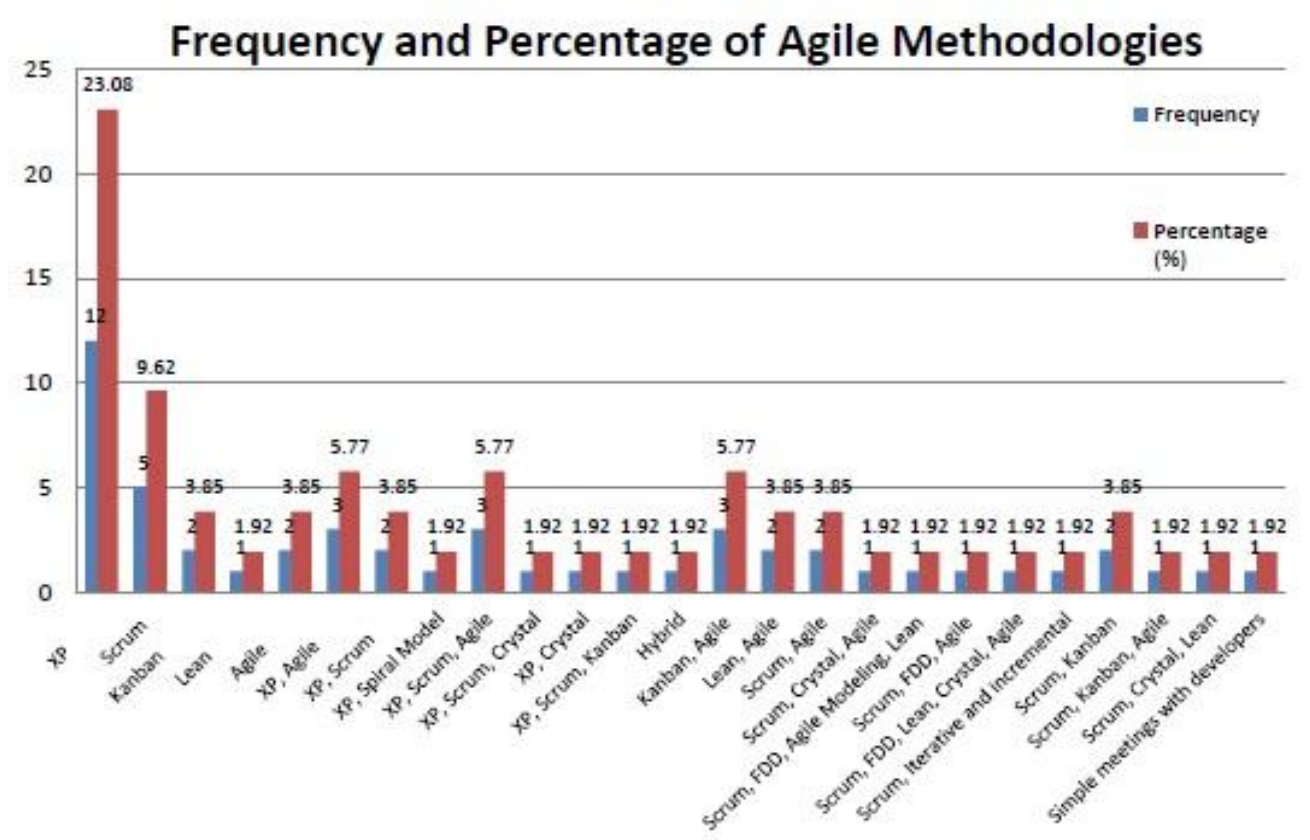

Figure 3. Agile methods used by Respondents

\subsection{Spearman's correlation to correlate the six-point star model factors}

The quality factor is one of the essential factors of six-point star model, which determines the requirements of customer's, software projects and as a whole success of the software product. Therefore, for this study, the quality factor is tested against the other factors of six-point star model. To test this relationship, a correlation technique is used to determine that how the quality factor effect on the other five factors, positively or negatively. The output showed that quality factors was positively correlated with other five factors, which determine that it is worth to examine the effect of agile methodologies on these factors. It further suggests that this might effect inclusive project success. Each factor of the six-point star model has two or more than two questions in the survey questionnaire and each question has assigned a numeric score, which is calculated for every factor. For example, the numeric score 5 is assigned to strongly agree, score 4 is assigned to agree and similarly, score 3 is assigned to neutral to questions number I, II and III. After calculating the average score for the schedule factor on the basis of respondent's feedback for these questions is 4.0. Therefore, after calculating the average score of schedule factor comes to 4.0.

A Spearman's Rank Order correlation technique was performed to conclude the association of quality factor with other five factors as shown in Table 6. A positive correlation was found between the quality factor and other factors. The results further recommended that there is also a significant correlation between the budget factor and the quality factor as compared to other factors, which were insignificantly correlated. As shown in Table 6, that the quality factor has a positive and insignificant correlation with the schedule factor i.e. $r s=0.1787$ with $p=0.20$. This leads the results that schedule of the project is imperative to improve the quality of the software project. The scope factor has a positive insignificant correlation with the quality factor i.e. $r s=0.0821$ with $p=0.56$. it is also found that the quality factor has a positive and significant relationship to the budget of the project, i.e. $r s=0.3362$ with $p=0.01$. According to Hair et al., the correlation coefficient is analytically defined in a range of values, for instance, if the coefficient is in the range of 0.2 to 0.4 is considered to be a small but definite, 0.4 to 0.7 range is considered to be moderate and a correlation coefficient of a range of 0.7 to 0.9 is considered to be a strong relationship [41]. These values suggested that the budget and quality factors are significantly correlated with each 
other. Therefore, it is very essential for the software professionals and companies to understand the importance of cost management in the software development projects [42].

A positive but insignificant correlation was found between the quality and risk factor i.e. $r s=0.0727$ with $p=$ 0.60. It means that risk factor need to be managed for improving the quality of the software. Similarly, the resource factor is also found positive but insignificant correlated with the quality factor i.e. $r s=0.1902$ with $p=0.17$. This suggests that resources for the software projects need to available for improving the quality of the software.

Table 6. Spearman's Correlation of PM factors

\begin{tabular}{|l|c|c|}
\hline Factors & $\begin{array}{c}\text { Spearman's Correlation } \\
\text { with quality factor }(r)\end{array}$ & Significance \\
\hline Schedule & 0.1787 & 0.20 \\
\hline Scope & 0.0821 & 0.56 \\
\hline Budget & $0.3362^{*}$ & 0.01 \\
\hline Risk & 0.0727 & 0.60 \\
\hline Resources & 0.1902 & 0.17 \\
\hline
\end{tabular}

The result shown in Table 6 indicates that all these factors have a positive impact in the successful software development. A lower positive correlation and significance level was found for schedule, scope, risk and resources factors, while budget showed significantly a higher correlation. But this does not mean that lower correlation coefficient level has no implication in terms of agile methodologies. Some of the studies wrongly interpreted the lower correlation coefficient considered as the different factors are not correlated significantly. Therefore, it still conceivable about the lower correlated coefficient value has significant consequences as it has observed in the results of this study.

\subsection{Comparison of agile methodologies and its affect on PM factors}

In this section, the agile methodologies are compared with respect to its affect on each factor of PM. As discussed each individual was free to choose one or more than one methodologies that they have used for their development purposes. Table 7 shows the results of all methodologies weather respondents used individually or as group. On the basis of our survey responses the mean and standard deviation values are computed according to the Likert scale scores for each individual survey question. As the survey data collected from 52 respondents and each PM factor has 2, 3 or 4 questions that results a total of 104, 156 and 208 scores. Therefore, on the basis of these scores the average and standard deviation of every PM factor is calculated for overall methodologies weather it is used by respondents individually or together. The results in Table 7 proposes that the mean values are not significantly dissimilar at the $95 \%$ confidence level, though, the results still achieved are interesting to be observed.

For example, in Table 7, we have only taken for discussion the mean column of XP, Scrum, Kanban, Lean and Agile methodology used individually by the respondents, the results proposed that Kanban is better than other four methodologies for the schedule factor (mean of 4.33 for Kanban against other means which is less than Kanban mean). For scope factor, Scrum and Agile have the same mean 4.00 while other methodologies mean are less than these two. For Budget factor, Scrum has 4.00 mean which are greater than other methodologies. For Risk factor, Kanban has 4.50 mean which are greater than other methodologies. For Resources factor, Agile has 4.25 mean which are greater than other methodologies. For quality factor, Scrum has 4.30 mean which are greater than other methodologies. These results showed that all these five methodologies have a positive effect on PM factors, like Kanban has an affect on schedule and risk factors, Scrum and Agile has an effect on scope factor, Scrum has also affected on budget and quality factors and Agile has an effect on resources factor. Table 7 also represents the mean and standard deviations of more than one methodologies used by the respondents.

Overall, our findings indicate that all agile methodologies have their own role in the success of software projects having an average scores of 4.0 for the quality factor (3.75 to 4.06 for XP, Scrum, Agile, Lean and Kanban respectively). Hence, on average the respondents given the responses with the "Agree" option to questions relating to the quality factor. Whether the agile methodology has to be used probably depends on the circumstances, technical wants, and available means of the project. 
Table 7. Mean and standard deviation values for all agile methodologies with respect to each PM factor

\begin{tabular}{|c|c|c|c|c|c|c|c|c|c|c|c|c|c|c|c|c|c|c|c|}
\hline \multirow{2}{*}{ S.NO } & \multirow{2}{*}{ AM } & \multicolumn{3}{|c|}{ S.F } & \multicolumn{3}{|c|}{ SOF } & \multicolumn{3}{|c|}{ B.F } & \multicolumn{3}{|c|}{ RF } & \multicolumn{3}{|c|}{ R.F } & \multicolumn{3}{|c|}{ QF } \\
\hline & & $\mathbf{M}$ & S.D & $\mathbf{N}$ & M & S.D & $\mathbf{N}$ & $\mathbf{M}$ & S.D & $\mathbf{N}$ & $\mathbf{M}$ & S.D & $\mathbf{N}$ & M & S.D & $\mathbf{N}$ & M & S.D & $\mathbf{N}$ \\
\hline 1 & $\mathrm{XP}$ & 3.88 & 0.53 & 12 & 3.75 & 0.81 & 12 & 3.58 & 0.66 & 12 & 3.83 & 0.77 & 12 & 3.50 & 0.67 & 12 & 4.06 & 0 & 12 \\
\hline 2 & Scrum & 3.86 & 0.50 & 5 & 4.00 & 0.61 & 5 & 4.00 & 0.79 & 5 & 3.40 & 0.54 & 5 & 3.90 & 0.22 & 5 & 4.30 & 0.20 & 5 \\
\hline 3 & Kanban & 4.33 & 0 & 2 & 3.25 & 0.35 & 2 & 3.00 & 0 & 2 & 4.50 & 0.70 & 2 & 350 & 1.41 & 2 & 4.12 & 0.53 & 2 \\
\hline 4 & Lean & 3.66 & 0 & 1 & 3.00 & 0 & 1 & 3.0 & 0 & 1 & 4.00 & 0 & 1 & 3.50 & 0 & 1 & 3.75 & 0 & 1 \\
\hline 5 & Agile & 4.16 & 0.23 & 2 & 4.00 & 0.70 & 2 & 3.5 & 1.41 & 2 & 4.25 & 0.35 & 2 & 4.25 & 1.06 & 2 & 3.75 & 0 & 2 \\
\hline 6 & $\mathrm{XP}$, Agile & 4.22 & 0.38 & 3 & 3.50 & 0.86 & 3 & 3.83 & 0.28 & 3 & 3.5 & 0.50 & 3 & 3.50 & 0.50 & 3 & 4.16 & 0.28 & 3 \\
\hline 7 & XP, Scrum & 4.49 & 0.23 & 2 & 4.00 & 0 & 2 & 3.75 & 0.35 & 2 & 4.25 & 0.35 & 2 & 425 & 0.35 & 2 & 4.12 & 0.17 & 2 \\
\hline 8 & XP, Spinal & 4.33 & 0 & 1 & 3.50 & 0 & 1 & 4 & 0 & 1 & 4.50 & 0 & 1 & 3.00 & 0 & 1 & 4.25 & 0 & 1 \\
\hline 9 & XP, Scrum, Agile & 4.33 & 0.32 & 3 & 4.50 & 0.50 & 3 & 4.33 & 0.76 & 3 & 4.00 & 0.50 & 3 & 4.33 & 0.28 & 3 & 4.33 & 0.52 & 3 \\
\hline 10 & XP, Scrum, Crystal & 3.33 & 0 & 1 & 4.50 & 0 & 1 & 3.5 & 0 & 1 & 4.00 & 0 & 1 & 3.00 & 0 & 1 & 4.0 & 0 & 1 \\
\hline 11 & $\mathrm{XP}$, Crystal & 4.33 & 0 & 1 & 3.50 & 0 & 1 & 4 & 0 & 1 & 3.50 & 0 & 1 & 3.50 & 0 & 1 & 4.25 & 0 & 1 \\
\hline 12 & $\mathrm{XP}$, Scrum, Kanban & 4.00 & 0 & 1 & 4.50 & 0 & 1 & 3 & 0 & 1 & 3.00 & 0 & 1 & 250 & 0 & 1 & 4.0 & 0 & 1 \\
\hline 13 & Hybrid & 3.66 & 0 & 1 & 2.50 & 0 & 1 & 3.5 & 0 & 1 & 3.00 & 0 & 1 & 2.00 & 0 & 1 & 3.50 & 0 & 1 \\
\hline 14 & Kanban, Agile & 4.33 & 0.32 & 3 & 3.83 & 0.57 & 3 & 3.83 & 0.76 & 3 & 3.83 & 0.28 & 3 & 3.33 & 0.76 & 3 & 4.16 & 0.28 & 3 \\
\hline 15 & Lean, Agile & 4.50 & 0.70 & 2 & 3.25 & 1.06 & 2 & 4.00 & 0.70 & 2 & 4.25 & 0.70 & 2 & 3.50 & .70 & 2 & 4.87 & 0.17 & 2 \\
\hline 16 & Scrum, Agile & 3.83 & 0.24 & 2 & 4.00 & 0.70 & 2 & 4.00 & 0.79 & 2 & 4.25 & 0.35 & 2 & 3.50 & 0 & 2 & 4.12 & 0.17 & 2 \\
\hline 17 & $\begin{array}{l}\text { Scrum, Crystal, } \\
\text { Agile }\end{array}$ & 3.66 & 0 & 1 & 3.00 & 0 & 1 & 4.00 & 0 & 1 & 4.00 & 0 & 1 & 3.00 & 0 & 1 & 4.00 & 0 & 1 \\
\hline 18 & $\begin{array}{l}\text { Scrum, FDD, Agile, } \\
\text { Lean }\end{array}$ & 5.00 & 0 & 1 & 4.00 & 0 & 1 & 5.00 & 0 & 1 & 4.00 & 0 & 1 & 4.50 & 0 & 1 & 4.75 & 0 & 1 \\
\hline 19 & Scrum, FDD, Agile & 4.33 & 0 & 1 & 3.00 & 0 & 1 & 4.00 & 0 & 1 & 4.50 & 0 & 1 & 3.00 & 0 & 1 & 4.50 & 0 & 1 \\
\hline 20 & $\begin{array}{l}\text { Scrum, FDD, Lean, } \\
\text { Crystal, Agile }\end{array}$ & 3.66 & 0 & 1 & 3.00 & 0 & 1 & 450 & 0 & 1 & 5.00 & 0 & 1 & 450 & 0 & 1 & 5.00 & 0 & 1 \\
\hline 21 & $\begin{array}{l}\text { Scrum, Iterative and } \\
\text { incremental }\end{array}$ & 4 & 0 & 1 & 2.50 & 0 & 1 & 3.00 & 0 & 1 & 4.00 & 0 & 1 & 3.00 & 0 & 1 & 3.75 & 0 & 1 \\
\hline 22 & Scrum, Kanban & 3.33 & 0 & 1 & 3.50 & 0 & 2 & 3.75 & 0.35 & 2 & 3.75 & 0.35 & 2 & 3.75 & 1.06 & 2 & 3.75 & 0 & 2 \\
\hline 23 & $\begin{array}{l}\text { Scrum, Kanban, } \\
\text { Agile }\end{array}$ & 3.99 & 0.47 & 2 & 3.00 & 0 & 1 & 4.00 & 0 & 1 & 4.00 & 0 & 1 & 4.00 & 0 & 1 & 4.25 & 0 & 1 \\
\hline 24 & $\begin{array}{l}\text { Scrum, Crystal, } \\
\text { Lean }\end{array}$ & 3.00 & 0 & 1 & 4.50 & 0 & 1 & 5.00 & 0 & 1 & 4.50 & 0 & 1 & 4.00 & 0 & 1 & 4.75 & 0 & 1 \\
\hline 25 & $\begin{array}{l}\text { Simple meetings } \\
\text { with develogers }\end{array}$ & 2.33 & 0 & 1 & 4.00 & 0 & 1 & 2.00 & 0 & 1 & 2.00 & 0 & 1 & 2.00 & 0 & 1 & 4.00 & 0 & 1 \\
\hline & Total & 399 & 0.53 & 52 & 3.71 & 0.70 & 52 & 3.75 & 0.70 & 52 & 3.87 & 0.64 & 52 & 3.57 & 0.71 & 52 & 4.14 & 0.39 & 52 \\
\hline
\end{tabular}

R.N=Respondent Number, A.M=Agile Methodology, M=Mean, S.D=Standard Deviation, N=Number of Respondents, S.F=Schedule Factor, SO.P= Scope Factor, B.F=Budget Factor, R.F=Risk Factor, R.F=Resource Factor, Q.F=Quality Factor

\section{Conclusion}

In software development, there is always a debate in choosing a software methodology. In this study, we statistically analyse the most broadly used agile methodology, to correlate the factors of six-point star model, and to compare the mostly used agile methodologies against the PM factors. Our obtained results recommended that XP has been used mostly by the software companies for software development in Pakistan followed by Scrum, AM and Kanban. The Spearman's Rank Oder correlation was used to correlate the factors of six-point star model, which shows that budget factor is positively significant correlation with the quality factor. It determines that the budget factors emphases on achieving the needs and attaining targeted return-on-investment (ROI). Additionally, the output recommended that each agile methodology has its own importance and effect in terms of managing different factors of PM.

A limitation of this study is the selection of respondents that strictly use agile methodologies instead of others. It could impact on the research of those respondents who like to work

in agile environment more than those respondents who do not want to work in this environment. Furthermore, this survey study was conducted only in Pakistani software companies. For the purpose it would be better to bring other respondents from other countries as well to avoid the results from being influence by a particular environment. In future, we are planning to analyze the effect of agile methods on productivity of software projects, team organization and management.

\section{Acknowledgment}

The authors wish to thank the Universiti Utara Malaysia for funding this study under University Research Grant Scheme, S/O project code: 13853 . 


\section{References}

1. C. Larman and V. R. Basili, "Iterative and incremental development: a brief history," IEEE Comput.Soc, vol. 36(6), 2003.

2. H. D. Benington, "Production of large computer programs,," Proceeding of the Navy Symposium on Advanced Programming Methods for Digital Computers Office of Naval Research, Department of the Navy Washington, DC, pp. 15-28, 1956.

3. B. Blanchard, Fabrycky, W. , "Systems Engineering and Analysis," Prentice Hall, Upper Saddle River, NJ, vol. 4th ed, 2011.

4. R. T. Futrell, Shafer, D.F., Shafer, L., "Selecting software development life cycles, Quality Software Project Management," Prentice Hall, Upper Saddle River, NJ, vol. 1st ed, pp. 101-161, 2002.

5. M. James, "Scrum Methodology 〈http://scrummethodology.com〉. (retrieved 8.04.15). ," 2009.

6. M. A. Awad, "A Comparison between Agile and Traditional Software Development Methodologies (Unpublished honours programme's dissertation), ," School of Computer Science and Software Engineering, The University of Western Australia,Crawley,WA,Australia. , vol. http://citeseerx.ist.psu.edu/viewdoc/summary?doi=10.1.1.464.6090, 2005.

7. "A Guide to the Project Management Body of Knowledge, Newtown Square, PA," Project Management Institute, vol. 47, 2008.

8. H. Lei, Ganjeizadeh, F., Jayachnadran, P. K., \& Ozcan, P., "A statistical analysis of the effects of Scrum and Kanban on software development projects, ," Robotics and Computer-Integrated Manafacturing 43, pp. 59-67, 2017.

9. A. Akbar, J. Sang, A. Khan, F. Amin, Nasrullah, M. Shafiq, et al., "Improving the Quality of Software Development Process by Introducing a New Methodology AZ-Model," IEEE Access, vol. 6, pp. 4811-4823http://doi.org/10.1109/ACCESS.2017.2787981, 2017.

10. A. Akbar, J. Sang, A. Khan, F. Amin, S. Hussain, M. Sohail, et al., "Statistical Analysis of the Effects of Heavyweight and Lightweight Methodologies on the Six-Pointed Star Model," IEEE Access, vol. 6, pp.8066-8079http://doi.org/10.1109/ACCESS.2018.2805702, 2018

11. K. Chari and M. Agrawal, "Impact of incorrect and new requirements on waterfall software project outcomes," Empirical Software Engineering, vol. 23(1), pp. 1-21, 2017.

12. A. Anderson, Beattie, R., Beck, K., "Chrysler Goes to Extremes," Distributed Computers, pp. 24-28., 1998.

13. K. Schwaber, " Controlled Chaos: Living on the Edge.," 1996.

14. C. Ladas, "Scrumban-Essays on Kanban Systems for Lean Software Development," Modus Cooperandi Press, Seattle., 2009.

15. A. Cockburn, "Crystal Clear a Human-Powered Methodology for Small Teams," Addison- Wesley, Reading, 2004.

16. M. Poppendieck and T. Poppendieck, "Lean Software Development: An Agile Toolkit.," Addison-Wesley, Boston, 2003.

17. S. Ambler, "The Agile Unified Process (AUP)," 2006.

18. P. Coad, de Luca, J., Lefebvre, E., "Java Modeling Color with Uml:," Enterprise Components and Process with Cdrom. Prentice Hall, Upper Saddle River., 1999.

19. P. Serrador and R. Turner, "The relationship between project success and project efficiency," Project Management Journal, vol. 46, pp. 30-39, 2015.

20. V. R. Basili and A. J. Turner, " Iterative Enhancement:A Practical Technique for Software Development.," IEEE Transactions on Software Engineering, vol. SE-1, pp. 390-396, 1975.

21. D. Cohen, M. Lindvall, and P. Costa, "An Introduction to Agile Methods," Advances in Computers, vol. 62, pp. 1-66, 2004.

22. F. Bauer, "Software Engineering," Information Processing vol. 71, 1972.

23. B. Boehm, "A Spiral Model of Software Development and Enhancement. ," Software Engineering Notes, vol. 11, pp. 14-24, 1986.

24. J. Iqbal, O. Mazni, and A. Yasin, "The impact of Agile methodologies and Cost Management Success Factors: An Empirical Study," Baghdad Science Journal, vol. 16, pp. 496-504, 2019.

25. K. Curcio, Malucelli, A., Reinehr, S., Paludo, M.A., "An analysis of the factors determining software product quality: A comparative study," Computer Standards\&Interfaces, 2016.

26. O. P. Sanchez, Terlizzi, M. A., Moraes, H.R., "Cost and time project management success factors for information systems development projects," International Journal of Project Management, vol. 35, pp. 1608-1626, 2017. 
27. D. Stankovica, V. Nikolicb, M. Djordjevicc, and D. B. Caod, "A survey study of critical success factors in agile software projects in former Yugoslavia IT companies," The Journal of Systems and Software, vol. 86, pp. 1663-1678 https://doi.org/10.1016/j.jss.2013.02.027, 2013.

28. J. Sheffield and J. Lemétayer, "Factors associated with the software development agility of successful projects," International Journal of Project Management, vol. 31, pp. 459-472 https://doi.org/10.1016/j.ijproman.2012.09.011, 2013.

29. P. Serrador and J. K. Pinto, "Does Agile work?-A quantitative analysis of agile project success," International Journal of Project Management, , vol. 33, pp. 1040-1051, 2015.

30. A. J. Sohia, M. Hertogha, M. Bosch-Rekveldta, and R. \& Blomb, "Does lean \& agile project management help coping with projectcomplexity? ," Procedia - Social and Behavioral Sciences, vol. 226 pp. 252 - 259 , 2016.

31. Z. Mansora, S. Yahyab, and N. H. Arshad, "Empirical Study of Cost Management Success Determinants in Agile Based Software Development Project: A Rasch Measurement Model Analysis," Procedia - Social and Behavioral Sciences, vol. 107, pp. 129 - 135 http://doi.org/10.1016/j.sbspro.2013.12.408 2013.

32. M. Jørgensen, "A survey on the characteristics of projects with success in delivering client benefits," Information and Software Technology, vol. 78, pp. 83-94 https://doi.org/10.1016/j.infsof.2016.05.008, 2016.

33. A. Shaikh, "The Role of Maturity Driven Software Process Improvement in an Inudstry," International Journal of Advanced Trends in Computer Science and Engineering, vol. 8, pp. 344-350https://doi.org/10.30534/ijatcse/2019/6081.12019), 2019.

34. G. Kannabiran, Sankaran, K., "Determinants of software quality in offshore development-An empirical study of an Indian vendor. ," Information and Software Technology. , vol. 53(11), pp. 1199-1208, 2011.

35. M. A. Umar, M. Ghazali, R. Saedudin, and M. Ashraf, "Meaasuring Software Product Quality using ISO 9126: A Systematic Review," International Journal of Advanced Trends in Computer Science and Engineering, vol. 8, pp. 327-336https://doi.org/10.30534/ijatcse/2019/6081.32019), 2019.

36. C. Chatfield and T. Johnson, "http://office.microsoft.com/en-us/project-help/ Project 2007 Step by Step.(retrieved14.07.12). ," 2007.

37. W. R. Duncan, "Project management processes, A Guide to Project Management Body of Knowledge,"D:AutomatedGraphicSystems, WhitePlains,, pp. 27-39, 1996.

38. J. F. Hair, W. C. Black, B. J. Babin, R. E. Anderson, and R. L. Tatham, "Multivariate Data Analysis," Pearson Prentice Hall, Upper Saddle River, , vol. 6, 2006.

39. A. Aron and E. Aron, "Statistics for psychology (2 ed.)," Upper Saddle River, NJ: Prentice Hall, 1999.

40. U. Sekaran and R. Bougie, "Research Methods for Business: A Skill-Building Approach. ," 6th Edition, Wiley, New York, 2013.

41. J. Hair, B. Babin, A. Money, and P. Samouel, "Essentials of Business Research Methods," International edition. Wiley, Hoboken (NJ), 2003.

42. S. R. Palmer, Felsing, M., " A Practical Guide to Feature-Driven Development," Prentice Hall PTR, Upper Saddle River, NJ., 2002. 